\title{
PENGARUH LATIHAN LONG PASSING MENGGUNAKAN SASARAN BERURUTAN TERHADAP KETEPATAN LONG PASSING DALAM PERMAINAN SEPAK BOLA
}

\author{
Raden Rizal Shufi Mubarok ${ }^{1)}$, H. Abdul Narlan ${ }^{2)}$, Haikal Millah ${ }^{3)}$ \\ ${ }^{1)}$ Universitas Siliwangi \\ ${ }^{2)}$ Universitas Siliwangi \\ ${ }^{3)}$ Universitas Siliwangi \\ email: rizallshuffi@gmail.com ${ }^{1)}$, abdulnarlan@unsil.ac.id ${ }^{2)}$, haikal@unsil.ac.id ${ }^{3)}$ \\ Abstrak \\ Tujuan dari penelitian ini adalah untuk memperoleh informasi tentang \\ Pengaruh Latihan Long Passing Menggunakan Sasaran Berurutan pada UKM Sepak \\ Bola Universitas Siliwangi 2019. Metode penelitian yang digunakan adalah metode \\ eksperimen. Berdasarkan hasil pengolahan data uji statistic, ternyata secara empirik \\ latihan long passing menggunakan sasaran berurutan berpengaruh terhadap ketepatan \\ long passing pemain UKM Sepak Bola Universitas Siliwangi 2019.
}

Kata kunci : Sasaran Berurutan, Ketepatan

\section{EFFECT OF LONG PASSING TRAINING USING A SEQUENTIAL TARGET TO THE ACCURACY OF LONG PASSING IN SOCCER GAMES}

\begin{abstract}
The purpose oh this study was to obtain information about the effect of long passing exercise using a sequential target at the 2019 siliwangi university soccer UKM. The research method used is the experimental method. Based on the results of data processing with statistical tests, it turns out that empirically long passing practice using successive targets influenced the long passing accuracy of 2019 Siliwangi University soccer UKM players.
\end{abstract}

Keywords: sequential targets, accuracy 


\section{PENDAHULUAN}

Sepak bola adalah cabang olahraga yang menggunakan bola yang umumnya terbuat dari kulit dan dimainkan oleh dua tim masingmasing beranggotakan 11 (sebelas) orang. Permainan sepak bola sering sekali dimainkan oleh masyarakat untuk kebugaran, rekreasi dan prestasi, sehingga tidak heran mengapa sepak bola menjadi cabang olahraga yang sangat popular dan digemari oleh seluruh lapisan masyarakat.

Pengertian sepak bola menurut (Sudjarwo, Iwan, 2017:1) "Sepak bola ialah olahraga beregu yang di dasari atas teknik, pengolahan bola, dan pengertian setiap pemain terhadap permainan". Ada beberapa teknik yang harus dikuasai oleh setiap pemain agar dapat bermain sepak bola dengan baik seperti yang dikemukakan (Sudjarwo, Iwan, 2017:1) dalam garis besarnya keterampilan dasar permainan sepak bola terdiri dari :

1. Teknik tanpa bola

Yaitu semua gerakan-gerakan tanpa bola terdiri dari :

a) Lari cepat dan merubah arah,

b) Melompat dan meloncat,

c) Gerak tipu tanpa bola yaitu gerak tipu tanpa badan,

d) Gerakan-gerakan khusus tanpa badan,

e) Gerakan-gerakan khusus untuk penjaga gawang.

2. Teknik dengan bola

Yaitu semua gerakan-gerakan tanpa bola terdiri dari :

a) Mengenal bola,

b) Menendang bola,

c) Menerima bola,

d) Menggiring bola (Dribbling),

e) Menyundul (Heading),

f) Melempar bola (Throw in), g) Teknik gerak tipu dengan bola,

h) Merampas atau merebut bola (Trackling),

i) Teknik-teknik khusus penjaga gawang.

Salah satu teknik yang harus dikuasai oleh setiap pemain yaitu teknik long passing, karena dengan teknik long passing pemain mampu mengumpan jarak jauh kepada teman sehingga dapat dijadikan cara untuk menciptakan peluang terjadinya gol. Hal tersebut sesuai dengan pendapat Herwin (Ghozali, Imam. 2013:) yaitu dalam permainan sepakbola menendang bola passing memiliki tujuan antara lain "Mengoper bola pada teman, mengoper bola ke daerah yang kosong, mengoper bola terobosan diantara lawan, menendang bola untuk membuat gol ke gawang lawan, dan menendang bola untuk menggunakan daerah permainannya sendiri".

Sedangkan Depdikpud (Alfian, Mufti:2012:18) menjelaskan sebagai berikut: "Long pass atau tendangan jarak jauh adalah mengoper bola ke teman yang berdiri jauh melalui tendangan". Maka dari itu dapat disimpulkan bahwa tendangan long passing merupakan salah satu teknik dasar sepak bola yang digunakan untuk mengumpan bola ke teman yang berdiri jauh dari tendangan.

Oleh karena itu, teknik dasar long passing harus dikuasai oleh pemain sepakbola, karena dengan menguasai tendangan long passing dapat digunakan untuk: "Tujuan menendang bola adalah untuk mengumpan (passing), menembak ke gawang (shooting at the goal) dan menyapu untuk menggagalkan serangan lawan (sweeping)". Sucipto,et al. (Alfian, Mufti 
2012:15).Maka dari itu dapat diambil kesimpulan bahwa long passing memiliki kegunaan untuk menembak bola ke gawang, menggagalkan serangan lawan pada saat melakukan taktik bertahan, mengumpan bola ke rekan tim yang berada jauh, dan melakukan serangan balik dalam proses menyerang atau pada saat penggunaan taktik menyerang. Oleh sebab itu maka setiap pemain harus menguasai teknik long passing supaya bisa memaksimalkan kegunaan long passing pada saat pertandingan.

Berdasarkan hasil observasi dan pengalaman selama berada di UKM sepak bola, peneliti melihat bahwa pada saat latihan beberapa pemain melakukan tendangan long passing yang ketepatan atau akurasi tidak tepat pada target atau rekan sehingga bola jatuh jauh dari target. Dan selain dari latihan pada saat pertandingan terlihat beberapa pemain melakukan hal yang sama dan itu diperkuat oleh pernyatan dari pelatih UKM sepak bola itu sendiri. Padahal pada proses latihan yang dilakukan oleh UKM sepak bola Universitas Siliwangi terdapat bentuk latihan teknik long passing yang diberikan oleh pelatih untuk menunjang taktik pada saat bertanding. Bentuk latihan long passing yang diberikan adalah latihan face to face long pass dengan jarak sekitar 15-20 meter.

$$
\text { Untuk meningkatkan }
$$

ketepatan teknik menendang long passing menggunakan kura-kura kaki bagian dalam maka dibutuhkan sebuah latihan yang terfokus pada ketepatan sasaran tendangan long passing. Mengenai bentuk latihan tendangan long passing, Soekatamsi (2004:119) mengungkapkan yaitu, Bentukbentuk latihan menendang bola dengan kura-kura kaki bagian dalam adalah sebagai berikut: 1) Latihan menendang bola pada tembok dan dinding yang diberi tanda sasaran. Pemain berdiri dengan jarak 8 sampai 17 meter di depan tembok, 2) Dua orang pemain saling berhadap-hadapan, ditengahtengahnya terdapat gawang, jarak masing-masing pemain dengan gawang 17 meter, 3) Dua pemain saling berhadap-hadapan dengan jarak 20 meter.

Selain itu bentuk latihan lain mengenai teknik menendang bola long passing menggunakan sasaran berurutan seperti yang diungkap oleh Chusairi (2009:53) bahwa "Mengarahkan bola dengan cermat dapat dilakukan dengan membuat tanda atau persegi $4 \times 4$ meter untuk dijadikan sasaran tendangan. Tendanglah ke arah sasaran ini berulang-ulang setelah ketrampilan bertambah baru melakukan ke sasaran lain".

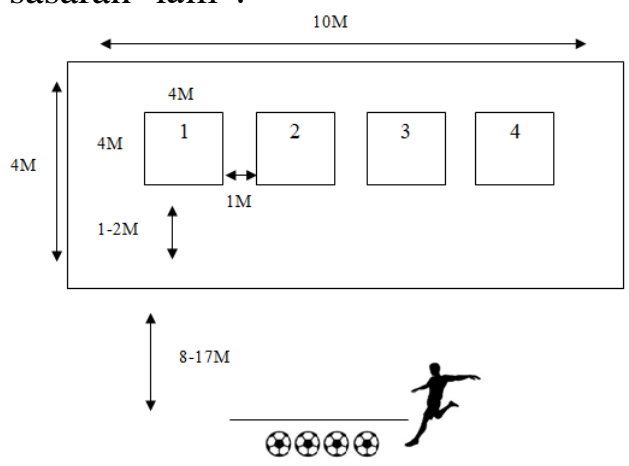

Gambar bentuk latihan long passing Berdasarkan uraian tersebut maka peneliti membuat sebuah penelitian mengenai tendangan long passing pada permainan sepak bola yaitu Pengaruh Latihan Long Passing menggunakan Sasaran Berurutan terhadap Ketepatan Long Passing dalam Permainan Sepak Bola (Eksperimen pada Anggota 
UKM Sepak Bola Universitas Siliwangi Tasikmalaya)".

\section{BAHAN DAN METODE}

Mengenai metode Widodo (2015:92) menjelaskan bahwa "Metode penelitian adalah suatu cara atau teknik yang digunakan dalam melakukan penelitian". Dari pendapat tersebut sesuai dengan permasalahan penelitian yaitu pengaruh latihan long passing menggunakan sasaran berurutan terhadap ketepatan long passing dalam permainan sepak bola. Oleh karena itu metode yang penulis gunakan dalam penelitian ini adalah metode eksperimen.

Mengenai penelitian

eksperimen, Harsono (2015:92)

menjelaskan bahwa "Metode eksperimen adalah metode penelitian yang digunakan untuk mencari pengaruh perlakuan tertentu terhadap yang lain dalam kondisi yang terkendalikan". Kutipan tersebut menjelaskan bahwa penelitian eksperimen selalu di lakukan dengan maksud untuk melihat akibat dari suatu pelakuan. Penerapan penelitian eksperimen ini, berarti penulis harus mengadakan kegiatan percobaan terhadap subjek yang akan menerima perlakuan tertentu dalam masa waktu tertentu (variabel bebas), kemudian setelah masa percobaan $i$ tu selesai selanjutnya dilihat hasil dari perlakuan tersebut pengaruhnya terhadap variabel terikat.

\section{Instrumen Penelitian}

Instrumen yang digunakan untuk memperoleh informasi mengenai long passing adalah tes ketermpilan long passing permainan sepak bola menurut Bobby Carlton (Ghozali, Imam 2013:33). Tes tendangan long passing Bobby Charlton adalah sebagai berikut (a) tentukan daerah $10 \mathrm{~m}^{2}$, (b) buat lagi tiga bidang persegi yang lebih kecil, bidang persegi yang paling tengah luasnya $4 \mathrm{~m}^{2}$, bidang berikutnya 6 $\mathrm{m}^{2}$, dan bidang ke tiga adalah $8 \mathrm{~m}^{2}$. (c) Setiap bidang memiliki nilai poin masing-masing, bidang yang paling tengah bernilai 100 poin, bidang berikutnya 50 poin, bidang berikutnya 40 poin, dan bidang yang paling luar bernilai 30 poin. Jarak bola yang ditendang sejauh 30 meter, semua tendangan dihitung dari titik tengah sasaran yang paling dalam (terkecil). Masing-masing pemain diberi 4 kali kesempatan menendang.

\section{Populasi dan Sampel}

Menurut Widodo (2017:92)

populasi adalah "Keseluruhan kelompok orang, kejadian atau hal minat yang ingin peneliti investigasi”. Apabila seseorang ingin meneliti semua elemen yang ada dalam wilayah penelitian, maka penelitiannya merupakan penelitian populasi. Populasi dibatasai sebagai jumlah kelompok atau individu yang paling sedikit mempunyai sifat yang sama.

Populasi yang digunakan dalam penelitian ini adalah Anggota UKM Sepak Bola Universitas Siliwangi Tasikmalaya yang berjumlah 40 orang. Menurut Widodo (2017:92) sampel adalah "Subkelompok atau sebagian dari populasi". Meskipun sampel hanya merupakan bagian dari populasi, kenyataan- kenyataan yang diperoleh dari sampel itu harus menggambarkan dalam populasi.

Teknik pengambilan data 
sampel ini biasanya didasarkan oleh pertimbangan-pertimbangan tertentu, misalnya keterbatasan waktu, tenaga dan dana sehingga tidak dapat mengambil sampel yang besar dan jauh. Adapun cara dalam penentuan sampel, penulis menggunakan cara purposive sampling. Menurut Widodo (2017:70) "Purposive sampling adalah apabila penentuan sampel didasarkan pada karakteristik atau ciri-ciri tertentu berdasarkan ciri atau sifat populasinya". Artinya setiap subjek yang diambil dari populasi dipilih dengan sengaja berdasarkan tujuan dan pertimbangan tertentu.

Pada pelaksanaanya, penulis mengambil sebagian dari populasi untuk menjadi sampel dengan kebutuhan penelitian dengan kriteria, sampel tidak cacat fisik terutama tangan dan kakinya dan dalam keadaan sehat. Kemudian penulis memilih dan menentukan populasi, jumlah sampel (subyek) penelitian sebanyak 20 orang, selanjutnya melakukan tes long passing.

\section{HASIL DAN PEMBAHASAN}

\section{Hasil}

$\begin{array}{lrr}\text { Latihan } & \begin{array}{r}\text { long } \\ \text { sasaran }\end{array} & \begin{array}{r}\text { passing } \\ \text { berurutan }\end{array} \\ \text { menggunakan } & \begin{array}{c}\text { saserpengaruh } \\ \text { secara }\end{array} & \text { signifikan }\end{array}$ terhadap peningkatan ketepatan long passing UKM Sepak Bola Universitas Siliwangi. Kebenaran hasil pengujian tersebut didukung pada data hasil penelitian dengan menggunakan uji $t$ yang menggunakan nilai thitung sebesar 484,62 yang berada di luar daerah penerimaan (ttabel sebesar 1,6)

Hal tersebut karena untuk menghasilkan hasil ketepatan dapat dilakukan dengan menggunakan latihan long passing menggunakan sasaran berurutan. Selain itu latihan long passing menggunakan sasaran berurutan diarahkan agar sesuai dengan tingkat perkembangan serta dapat membantu dan mendorong perubahan kemampuan-kemampuan sesuai dengan tujuan latihan tersebut.

\section{Pembahasan}

Bentuk latihan untuk sebuah teknik dasar harus dikembangkan supaya lebih cepat mengarah pada pencapaian tujuan. Dalam sepak bola terdapat berbagai macam teknik dasar, salah satunya adalah long passing. Teknik long passing digunakan ketika memberikan umpan pada teman yang jaraknya jauh, sehingga menuntut koordinasi fisik dan teknik yang baik untuk menciptakan akurasi yang tepat. Oleh karena itu, dibutuhkan sebuah bentuk latihan yang memang mengarah pada tingkat ketepatan hasil long passing.

Bentuk latihan long passing dalam penelitian ini sangat tepat sekali adanya dikarenakan terdapat sasaran yang dijadikan target oleh para sampel dalam melakukan latihan long passing. Maka data hasil penelitian membuktikan bahwa dengan bentuk latihan long passing menggunakan sasaran berurutan dapat meningkatkan kualitas ketepatan tendangan long passing dalam permainan sepak bola.

\section{KESIMPULAN DAN SARAN Simpulan}

Berdasarkan hasil penelitian, analisis data dan pengujian hipotesis dengan menggunakan pendekatan statistik, penulis menyimpulkan sebagai berikut: "Latihan latihan long passing menggunakan sasaran berurutan berpengaruh secara signifikan terhadap ketepatan long passing 
permainan sepak bola pada anggota Unit Kegiatan Mahasiswa Universitas Siliwangi Tasikmalaya”. Hal ini berarti bahwa latihan long passing menggunakan sasaran berurutan efektif digunakan dalam meningkatkan ketepatan long passing permainan sepak bola.

\section{Saran}

Penulis menyarankan beberapa hal dalam penelitian ini, sebagai berikut:

1. Untuk meningkatkan keterampilan long passing permainan sepak bola penulis menyarankan, agar hasil penelitian ini dapat dijadikan tolak ukur dan dapat digunakan sebagai pilihan bentuk latihan berupa alat bantu sasaran dalam rangka peningkatan keterampilan long passing permainan sepak bola.

2. Karena ruang lingkup penelitian ini terbatas, penulis menyarankan kepada berbagai pihak yang tertarik untuk membahas dan meneliti mengenai masalah yang sama, agar melakukan penelitian lebih lanjut dengan menggunakan ruang lingkup penelitian yang lebih luas sehingga diperoleh hasil yang lebih empirik, misalnya dengan menggunakan sampel siswa/siswi SD, SMP, SMK, atau atlet yang profesional.

\section{DAFTAR PUSTAKA}

Alchamat, Adel. (2011). Passing

Lofted Pass. [Online].

Tersedia :

https://www.sportsessionplan

ner.com/s/uLEab/Passing-

Lofted-

Pass.html?interface $=$ en. $[29$
April 2019]

Arikunto, Suharsimi. (2013).

Prosedur Penelitian. Jakarta: Rineka Cipta.

Badriah, Dewi Laelatul. (2013). Fisiologi Olahraga. Bandung: Pustaka Ramadhan.

Chusairi. (2009). Pembinaan Taktik dan Teknik Sepak bola. Jakarta. Mutiara Sumber Widya.

Dewi, et.al. (2016). Hubungan Kekuatan Otot Tungkai Dengan Kemampuan Menendang Bola Dalam Permainan Sepak Bola Siswa Di SMA Negeri 1 Karangtengah Kabupaten Demak. (Skripsi). Surakarta. UMS.

Ghozali, Imam. (2013). Ketepatan Long Passing Pemain UKM Sepak Bola Uniersitas Negeri Yogyakarta. (Skripsi). Yogyakarta. UNY.

Haerudin, Yuyud Said. (2015). Pengaruh Latihan Menggunakan Alat Bantu Tahanan Karet dan Pemberat Kaki Terhadap Power Tungkai dan Implikasi Pada Long Passing Cabang Olahraga Sepakbola. [Online]. Tersedia : repository.upi.edu/18007/. (26 April 2019).

Harsono. (2015). Kepelatihan Olahraga : Teori dan Metodologi. Bandung : Remaja Rosdakarya. 
Harsono. (2018) Latihan Kondisi Fisik. Bandung: PT Remaja Rosdakatya.

Koger, Robert. (2007). Latihan Dasar Andal Sepak Bola Remaja. Klaten : Saka Mitra Kompetensi.

Kamus Besar Bahasa Indonesia. (2016). Kamus Besar Bahasa Indonesia. [Online]. Tersedia https://kbbi.kemdikbud.go.id/e ntri/pengaruh. (21 Januari 2019)

Kusnadi, Nanang Dan Herdi Hartadji. (2014) Ilmu Kepelatihan Dasar. Tasikmalaya: Program Studi Pendidikan Jasmani, Kesehatan Dan Rekreasi, Universitas Siliwangi.

Narlan, Abdul. (2017) Hand Out Statistika. Tasikmalaya: Program Studi Pendidikan Jasmani, Kesehatan Dan Rekreasi, Universitas Siliwangi.

Nurdiansyah. (2018). "Kontribusi Daya Ledak Tungkai, Kecepatan Reaksi Kaki dan Keseimbangan Terhadap Kemampuan Menendang Bola Pada Murid SD Negeri 22 Maros". (Skripsi). Makassar. FIK UNM .

Nurhasan dan Abdul Narlan. (2017) Tes Dan Pengukuran Pendidikan Olahraga. Tasikmalaya: Program Studi Pendidikan Jasmani, Kesehatan Dan Rekreasi, Universitas Siliwangi.
PSC.(2019).Professional Soccer Coaching.[Online].Tersedia: https://www.professionalsocc ercoaching.com/passing-andcontrol/aerial-a-longpassing\#tab-4 . [29 April 2019].

Pusat Bahasa Depdiknas. (2001). Kamus Besar Bahasa Indonesia . Jakarta: Balai Pustaka.

Sudjarwo, Iwan. (2015). Permainan Sepak Bola. Tasikmalaya: PJKR FKIP UNSIL. Sudjarwo, Iwan. (2017). Permainan Sepak Bola. Tasikmalaya: PJKR FKIP UNSIL. Soekatamsi. (2004). Teknik Dasar Bermain Sepak bola. Solo. TigaSerangkai.

Sugiyono. (2015). Statistika untuk Penelitian. Bandung : CV. Alfabeta.

Sugiyono. (2012) Metode Penelitian Kuantitatif, Kualitatif, Dan $R \& D$. Bandung: Alfabeta.

Sugiyono. (2017) Metode Penelitian Kuantitatif, Kualitatif, Dan $R \& D$. Bandung: Alfabeta.

Widodo. (2017). Metodologi Penelitian. Jakarta. PT. Raja Grafindo Persada 